\title{
Comparison of Body Composition among Newly Entered Medical and Nursing/Midwifery Students of Rafsanjan University of Medical Sciences
}

\author{
Salem Z, MSc ${ }^{1}$, Sheikh Fathollahi M, $\mathrm{PhD}^{2 *}$, Hashemi Z, MSc ${ }^{3}$, Shahabinejad M, MSc ${ }^{4}$ \\ 1- Faculty Member, Dept. of Social Medicine and Occupational Environment Research Center, Medical School, Rafsanjan \\ University of Medical Sciences, Rafsanjan, Iran. 2- Assistant Prof., Dept. of Social Medicine and Occupational Environment \\ Research Center, Medical School, Rafsanjan University of Medical Sciences, Rafsanjan, Iran. 3- Faculty Member, Medical \\ School, Rafsanjan University of Medical Sciences, Rafsanjan, Iran.4- Faculty Member, Dept. of Medical Surgical, School of \\ Nursing and Midwifery, Rafsanjan University of Medical Sciences, Rafsanjan, Iran.
}

\begin{abstract}
Received: May 2015, Accepted: August 2015

Background: It seems that weight gain and body composition changes occur during the first year of college. The aim of this study was the comparison of body composition among freshmen medical sciences students one term after entering Rafsanjan University of Medical Sciences, South East of Iran.

Materials and Methods: All freshmen medicine $(\mathrm{n}=73)$ and nursing-midwifery students $(\mathrm{n}=57)$ of Rafsanjan University of Medical Sciences who had registered for the fall of 2013 were participated in this descriptive study. After obtaining written consents from the participants, their demographic information was collected. Then, using bioelectrical impedance analysis (BIA), body composition of all the students was measured and recorded. Data were analyzed using independent two-sample t-test, paired t-test, and Wilcoxon signed-ranks test.

Results: The difference between medical and nursing/midwifery students in terms of changes in body fat percentage $(1.92 \pm 2.87$ versus $-0.29 \pm 2.21$, respectively) $(\mathrm{P}<0.001)$ and body water content $(-0.13 \pm$ 1.34 versus $0.35 \pm 1.20$, respectively $(\mathrm{P}=0.038)$ was statistically significant. Moreover, the difference in changes of fat free mass was statistically significant across the two groups $(P=0.026)$. Body fat percentage had decreased in the native students compared to the nonnatives $(\mathrm{P}<0.001)$. The frequency of students with malnutrition and minimum fat percentage criteria had decreased, while it had increased to the recommended range at the end of the first semester.

Conclusions: There was a statistically significant difference between medical and nursing/midwifery students in terms of fat percentage, fat free mass, and total body water content. It seems that the differences between the two groups might be because of being native or nonnative students.
\end{abstract}

Keywords: Body Composition, Medical Students, Nursing Students, Waist Circumference

\section{Introduction}

It has been reported that weight maintenance and decrease the prevalence of obesity in youth and adults are very important factors for prevention of chronic diseases. A strategy for prevention of obesity is to identify critical periods of weight gain in the human life cycle (1).

It seems that weight gain occurs during the first year of college (2). Weight gain and lifestyle changes in this period may contribute to obesity in the adulthood period (3). The greatest increases in weight seem to occur in youth between the ages 18 and 29 years $(3,4)$. During the college years, increase in weight and fat percentage is equal to $1.55 \mathrm{~kg}$ and $1.17 \%$, respectively (5). The study by Elizabeth showed

\footnotetext{
* Corresponding author: Mahmood Sheikh Fathollahi, Dept. of Social Medicine, Medical School, Rafsanjan University of Medical Sciences, Rafsanjan, Iran. Email: mamoosh502002@yahoo.com
} 
overweight/obesity rates increased in freshmen students until the end of the year (6). Body mass index (BMI) is used to detect obesity and underweight, but this index is not able to distinguish the differences in fat percentage and lean body mass. Recently, the use of this index has been the subject of some disagreements. To overcome the problem, different methods have been introduced to measure body composition and fat percentage (7).

Among the existing methods, bioelectrical impedance analysis (BIA) is a safe, accurate, reliable, and inexpensive method of screening for overweight and obesity (8). This method is able to estimate body fat percentage (BFP), fat mass, lean body mass, BMI, and total body water $(9,10)$. Results of a study indicated that measures by BIA were different with anthropometric indices (7). Another study indicated that BMI has limitations in predicting an individual's BFP and the sensitivity is low compared to other methods (11). Goonasegaran et al. compared the effectiveness of BFP and BMI in determination of body composition; people with BFP of 22.8 and BMI of $33.8 \mathrm{~kg} / \mathrm{m}^{2}$ were classified as either obese or overweight (12). This study indicated that BFP plays a more important role in distinguishing obesity and has more power in the differentiation of BFP and lean body mass (12). However, an earlier study reported different results (7). Further studies and comparisons should be conducted between body composition and BMI in different age and sex groups.

Due to the transition from high school to university, new entry and freshmen students are subject to changes in dietary habits and lifestyle (13). Frajian showed that $48.6 \%$ of female students had increased fat mass and body fat distribution (waist circumference and waist to hip ratio) which is related to cardiovascular disease risk factor (14). The majority of studies, such as Mohamadie's report, have reported the prevalence of overweight or obesity and underweight among students over a short period of time (15). Freshmen students are at higher risk of weight gain (16). Furthermore, there have been no previous studies comparing body composition changes in freshmen students of Rafsanjan University of Medical Sciences, Iran. Therefore, this study was conducted with the aim of comparing the body composition of freshmen medical sciences students one term after entering Rafsanjan University of Medical Sciences, South East of Iran.

\section{Materials and Methods}

In this descriptive study (measurements performed at two time periods), all the freshmen medicine (73 participants) and nursing and midwifery students were studied (57 participants). During the registrations (fall 2013), all the students of the government university in South East of Iran (Rafsanjan University of Medical Sciences) were invited to participate in the study.

Students under 17 years of age or with a history of eating disorders or a major chronic disease (diabetes, hypertension, or heart, lung, or kidney disease), and pregnant students were excluded from the study. After obtaining written consent forms from the participants, individual demographic questionnaires were completed. Demographic information, such as age, gender, marital status, regular exercising (yes, no), eating breakfast and snacks (yes, no), and residential status (native, nonnative), were obtained. The ethics committee of Rafsanjan University of Medical Sciences approved the study and students were assured of confidentiality.

Anthropometric indices, including height and waist circumference (WC), were measured using a non-elastic meter. All criteria were measured twice; at the time of admission into the university and after the first semester (or after 16 
weeks). BIA (TANITA-300A, Japan) was used for composition measurements (BFP, lean body mass, fat mass, BMI, and total water). Trained assistants measured students' body composition. All measurements were performed in accordance with the manufacturer's instructional manual. The participants stood on the flat surface of the scale without shoes, socks, or electronic devices. Students with implanted cardiac stent(s) or pacemaker(s) were excluded from the study. Salem et al. have described the complete measurement method of BIA (17). According to $\mathrm{BFP}$, students were categorized into 3 groups including minimum, recommended, and obese according to age and gender (18). Students' BMI was also classified as underweight $(<18.5$ $\left.\mathrm{kg} / \mathrm{m}^{2}\right)$, normal $\left(18.5-24.9 \mathrm{~kg} / \mathrm{m}^{2}\right)$, overweight $\left(25-29.9 \mathrm{~kg} / \mathrm{m}^{2}\right)$, and obese $\left(\geq 30 \mathrm{~kg} / \mathrm{m}^{2}\right)$. Distribution of body fat was determined using waist circumference, and abdominal obesity was defined as over $80 \mathrm{~cm}$ and over $92 \mathrm{~cm}$ for girls and boys, respectively (19). All the anthropometric indices and body compositions were measured at the beginning and end of the first semester. All the participating students completed the follow-up measurements.

Results are presented as mean \pm standard deviation (SD) for numeric variables, and are summarized by absolute frequencies and percentages for categorical variables. Continuous variables were compared using independent two-sample t-test across the two study groups. One-sample Kolmogorov-Smirnov test was used to test the normal distribution of data. No statistically significant violation of normality was observed. Continuous variables were compared using paired t-test at the time of admission and the end of the first semester among all students. Non-parametric Wilcoxon signed-ranks test was used to compare the students' body composition at the time of admission and end of the first semester. For statistical analysis, SPSS statistical software for windows (version 15, SPSS Inc., Chicago, IL,
USA) was used. All P values were 2-tailed, with statistical significance defined as $\mathrm{P} \leq 0.050$.

\section{Results}

The demographic information indicated that $66.2 \%$ (86 students) of the participants were women and $33.8 \%$ (44 students) were men. There was no significant statistical difference between the two groups in terms of gender $(\mathrm{P}=$ 0.219). The mean age of the medical students and nursing/midwifery students was $19.34 \pm$ 2.62 years and $19.12 \pm 0.83$ years, respectively $(\mathrm{P}=0.543)$. There were more nonnative students among medical students than nursing/midwifery students (90.4\% and $64.9 \%$, respectively). This difference between the two groups of students was statistically significant $(\mathrm{P}<0.001)$. No significant differences were found between the two groups in terms of marital status $(\mathrm{P}=$ $0.533)$, doing regular exercise $(\mathrm{P}=0.111)$, and eating breakfast and snacks $(\mathrm{P}=0.672, \mathrm{P}=$ 0.263 , respectively).

Table 1 shows the mean changes of the different variables at the end of the semester. The difference in changes of fat percentage and body water content among the two groups were statistically significant $(\mathrm{P}<0.001$ and $\mathrm{P}=0.038$, respectively). Fat percentage was reduced in the nursing/midwifery students, while it showed an increase in the medical students. Body water content was reduced in medical students, whereas it increased in nursing/midwifery students at the end of the study. The difference in changes of fat free mass among the two groups was statistically significant $(\mathrm{P}=0.026)$; it had increased in nursing/midwifery students, while it had decreased in medical students. The differences in changes of other variables between the two groups were not statistically significant, although they had increased in both groups at the end of the first semester, except for WC which had decreased in nursing/midwifery students. 
Table1: Comparison of mean changes of variables between medicine and nursing/midwifery students at the end of the semester in Rafsanjan University of Medical Sciences, Iran, in 2013

\begin{tabular}{lccc}
\hline \multicolumn{1}{c}{ Variables } & $\begin{array}{c}\text { Medical students } \\
(\mathbf{n}=\mathbf{7 3})\end{array}$ & $\begin{array}{c}\text { Nursing/Midwifery students } \\
(\mathbf{n}=\mathbf{5 7})\end{array}$ & P-value* $^{*}$ \\
\hline Weight $(\mathrm{kg})$ & $0.65 \pm 2.93$ & $0.18 \pm 1.54$ & 0.243 \\
\hline Height $(\mathrm{cm})$ & $0.20 \pm 0.46$ & $0.11 \pm 0.31$ & 0.171 \\
\hline BMI $\left(\mathrm{Kg} / \mathrm{m}^{2}\right)$ & $0.19 \pm 1.06$ & $0.06 \pm 0.56$ & 0.373 \\
\hline Waist circumference $(\mathrm{cm})$ & $0.05 \pm 2.99$ & $-0.37 \pm 2.83$ & 0.410 \\
\hline Body fat $(\%)$ & $1.92 \pm 2.87$ & $-0.29 \pm 2.21$ & $<0.001$ \\
\hline Body mass $(\mathrm{Kg})$ & $0.68 \pm 4.78$ & $0.51 \pm 5.71$ & 0.854 \\
\hline Fat free mass $(\mathrm{kg})$ & $-0.19 \pm 1.82$ & $0.50 \pm 1.62$ & 0.026 \\
\hline Total body water $(\mathrm{kg})$ & $-0.13 \pm 1.34$ & $0.35 \pm 1.20$ & 0.038 \\
\hline
\end{tabular}

${ }^{*} \mathrm{P}<0.050$ was considered a statistically significant difference.

Data are presented as mean \pm SD.

Mean changes were compared using independent two-sample t-test across the two groups.

Table 2 shows that BFP decreased in native students at the end of the term compared to nonnatives $(\mathrm{P}<0.001)$. Both girls and boys showed an increase in height, but this increase was greater in boys $(P=0.009)$. In contrast, at the end of the study, BMI of the boys had reduced, while BMI of the girls had increased $(\mathrm{P}=0.031)$. Other variables were not statistically significant according to residential status and gender; these variables are not presented in table 2 .

Table 2: Comparison of mean variables at the two time periods according to residential status and gender of students in Rafsanjan University of Medical Sciences, Iran, in 2013

\begin{tabular}{lccccc}
\hline Variables & Entrance Time & First semester & Mean changes & P-value $^{*}$ & P-value** $^{* *}$ \\
\hline Body fat $(\%)$ & & & & & $<0.001$ \\
$\quad$ Native $(\mathrm{n}=27)$ & $21.70 \pm 9.49$ & $20.94 \pm 9.55$ & $-0.77 \pm 2.23$ & 0.086 & \\
$\quad$ Nonnative $(\mathrm{n}=103)$ & $18.20 \pm 10.21$ & $19.60 \pm 9.46$ & $1.40 \pm 2.79$ & $<0.001$ & \\
\hline BMI & & & & & 0.031 \\
$\quad$ Girls $(\mathrm{n}=86)$ & $21.93 \pm 4.14$ & $22.18 \pm 3.96$ & $0.25 \pm 0.88$ & 0.009 & \\
$\quad$ Boys $(\mathrm{n}=44)$ & $23.64 \pm 5.70$ & $23.55 \pm 5.25$ & $-0.10 \pm 0.83$ & 0.448 & \\
\hline Height & & & & & 0.009 \\
$\quad$ Girls $(\mathrm{n}=86)$ & $160.10 \pm 5.42$ & $160.17 \pm 5.42$ & $0.08 \pm 0.26$ & 0.009 & \\
$\quad$ Boys $(\mathrm{n}=44)$ & $175.34 \pm 5.63$ & $175.66 \pm 5.57$ & $0.32 \pm 0.56$ & 0.001 & \\
\hline
\end{tabular}

${ }^{*} \mathrm{P}<0.050$ was considered a statistically significant difference across the two time periods.

${ }^{* *} \mathrm{P}<0.050$ was considered a statistically significant difference across the two mean changes.

Data are presented as mean \pm SD.

Mean changes were compared using independent two-sample t-test across groups.

The Wilcoxon signed-rank test revealed that the frequency distribution of students' body composition (only BFP) statistically differed at the end of study compared to the time of admission $(P=0.005)$. Thus, the distribution of students had shifted from "malnourished or minimum status" towards "recommended status" by the end of the study. Based on BMI and WC, measures of underweight and obesity were seen in both medical and nursing/midwifery students at admission and the end of the first term. Nevertheless, the differences of underweight and obesity were not statistically significant across the two time periods in either groups $(\mathrm{P}>$ 
0.050). While, based on BFP, the difference of underweight and obesity was statistically significant in medical students between the two time periods (beginning and end of the term) $(\mathrm{P}$ $=0.003)$. As figure 1 shows, the pattern of BFP changes in medical students was the same.

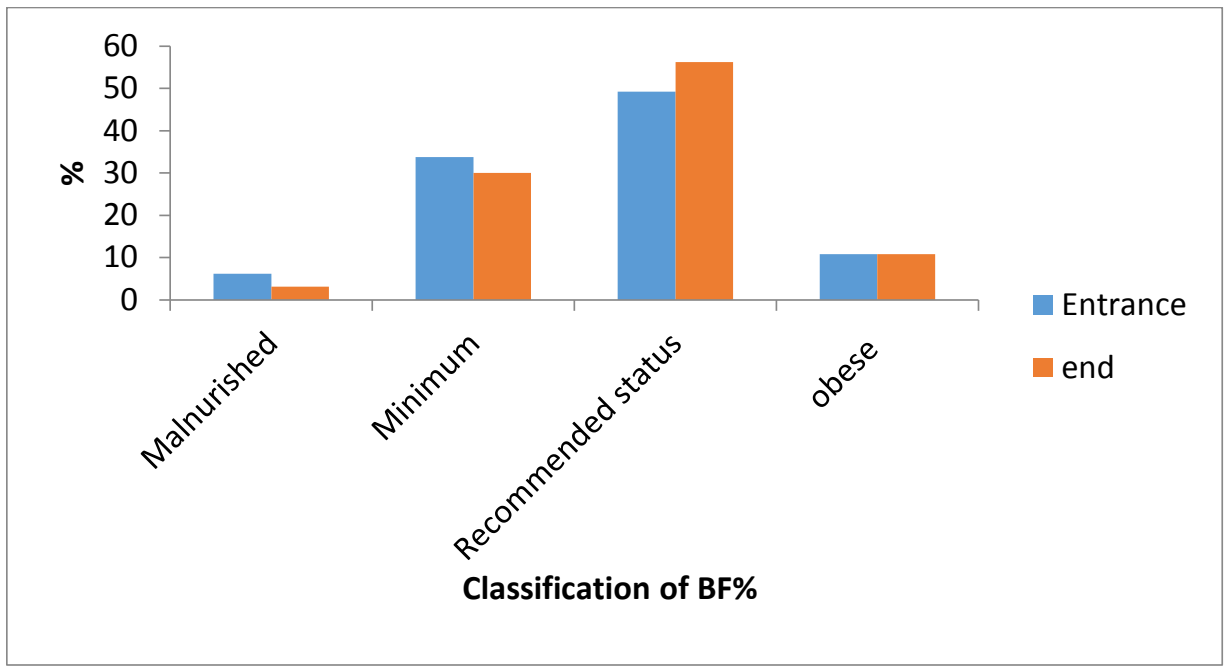

Figure 1: Frequency distribution of students based on body fat percentage (BFP) at admission and the end of study in Rafsanjan University of Medical Sciences, Iran, in 2013

\section{Discussion}

Transition from adolescence to adulthood can cause changes in body composition. These changes differed among the nursing/midwifery students and medical students of Rafsanjan University of Medical Sciences in. Results of the current study showed that BFP of the nursing students had decreased, but for the medical students, this variable had increased $(\mathrm{P}<0.001)$. Fat free mass had increased in nursing/midwifery students, but had decreased in medical students $(\mathrm{P}=0.026)$. Furthermore, body water level had decreased in medical students compared to nursing/midwifery students $(\mathrm{P}=$ 0.038). This discrepancy is not unexpected, because body water has a reverse association with BFP, and BFP had increased in medical students.

Shimbo et al. reported that $29 \%$ of students lived in their homes and $42 \%$ lived in the dormitory. Native students had more optimal nutritional status, had enough energy, had a high protein intake, and had not skipped breakfast. Living at their family homes had helped them to have better nutritional habits (20). The study by Newton indicated that stress can have a double effect on the appetite of the students, and an increase or decrease of appetite could lead to obesity or underweight, respectively (21). Papadaki et al. found no significant difference in nutritional habits of native and nonnative students, although nonnatives had shown a decrease in fruits and vegetables intake and an increase in consumption of fast foods.

This study indicated that admission to the university caused unfavorable patterns in nutritional habits for the nonnative students compared to the native students (22). A systemic review study has shown that change in body weight and BFP during the first year of college is significantly less than that during the subsequent years of college (1). Therefore, results of the present study are comparable with these studies. This difference between the two groups may be due to the difference in the residential status of the students, as $90.4 \%$ of 
medical students and $64.9 \%$ of nursing/midwifery students were nonnatives. Furthermore, living in the dormitory may have affected the nonnative medical students in a way that may have changed their nutritional habits towards increasing BFP. Moreover, there was an increase in the stress level of these students due to the difficulty of study courses, curriculum load, and being away from home. In addition, being away from home and not having enough time to prepare food resulted in them eating meals at the university restaurants and having more fast food. These factors may have led to an increase in BFP in the medical students.

According to residential status, results revealed that BFP decreased in native students, while it increased among nonnative students. Stress might possibly have been a factor in decreasing the appetite, and thus, causing this change. In the study by Newton, in $35 \%$ of the students, their appetite had decreased due to stress (21).

Based on gender, BMI decreased in boys, while it increased in girls $(P=0.031)$. The increase in height in the boys was greater than in the girls $(\mathrm{P}$ $=0.009)$. It seems that further increase in the height of boys also led to the reduction of their BMI, whereas the increase in BMI in girls led to lower increase in their height. It seems that girls are at higher risk of overweight and affected more by nutritional status and environmental factors compared to boys (23).

The comparison of the variables using Wilcoxon signed-rank test based on BFP distribution of students showed that it shifted from "malnourished or minimum status" towards "recommended status" by the end of study. This finding is in line with the study by Newton et al. $(21,23)$. The transition from high school to university and the generated stresses in the first year at the university could have a joint effect with the students' appetite and body composition. As in the study by Newton, in our study, $63 \%$ of the participants had experienced an increase in their appetites (21). It is likely that an increase in appetite had shifted their BFP to the recommend level which is a good status for students. Optimum level BFP, as a nutritional indicator, has a great role in survival, prevention of infectious diseases, and promotion of the immune system.

This study indicated statistically significant differences in fat percentage, fat free mass, and total body water between the two groups. It seems these observed changes during the first semester of college is an expectable phenomenon and may be attributed to environmental factors (24). Therefore, it seems that these differences between the two groups might be due to the differences in students' residential status. As there were more nonnatives among medical students than nursing students, they were affected by the new environmental status and university restaurant's food more than the other groups. It seems that more studies are needed to follow these changes in students until their graduation.

\section{Conclusion}

In this study, it was shown that, after admission to the university, changes occur in the body composition of students and these changes lead to better or worse nutritional status. It seems necessary to examine these changes at the time of graduation to better understand which index changes more compared to other indices.

\section{Acknowledgment}

The authors would like to sincerely thank the students who agreed to participate in this study and Mrs. Khoshooii and Abin who helped in the data gathering process.

Conflict of interest: None declared. 


\section{References}

1. Anderson DA, Shapiro JR, Lundgren JD. The freshman year of college as a critical period for weight gain: an initial evaluation. Eat Behav 2003; 4(4):363-7.

2. Hajhosseini L, Holmes $\mathrm{T}$, Mohamadi $\mathrm{P}$, Goudarzi V, McProud L, Hollenbeck CB. Changes in body weight, body composition and resting metabolic rate (RMR) in first-year University Freshmen Students. J Am Coll Nutr 2006; 25(2):123-7.

3. Racette SB, Deusinger SS, Strube MJ, Highstein GR, Deusinger RH. Weight changes, exercise, and dietary patterns during freshman and sophomore years of college. J Am Coll Health 2005; 53(6):245-51.

4. Hull HR, Morrow ML, Dinger MK, Han JL, Fields DA.

Characterization of body weight and composition changes during the sophomore year of college. BMC Womens Health 2007; 7:21.

5. Fedewa MV, Das BM, Evans EM, Dishman RK. Change in weight and adiposity in college students: a systematic review and meta-analysis. Am J Prev Med 2014; 47(5):64152.

6. Lloyd-Richardson EE, Bailey S, Fava JL, Wing R. A prospective study of weight gain during the college freshman and sophomore years. Prev Med. 2009; 48(3):256-61.

7. Kęska A, Tkaczyk J, Czajkowska A, Wiśniewski A, Norkowski H, Smolarczyk M, et al. [Fat content in young adults determined by skinfolds and body composition analyzator]. Pediatr Endocrinol Diabetes Metab 2012; 18(1):33-6.

8. Amani R. Comparison between bioelectrical impedance analysis and body mass index methods in determination of obesity prevalence in Ahvazi women. Eur J Clin Nutr 2007; 61(4):478-82.

9. Dehghan M, Merchant AT. Is bioelectrical impedance accurate for use in large epidemiological studies? Nutr J 2008; 7:26.

10. Gropper SS, Newton A, Harrington P, Simmons $\mathrm{KP}$, Connell LJ, Ulrich P. Body composition changes during the first two years of university. Prev Med 2011; 52(1):20-2.

11. Arroyo M, Rocandio AM, Ansotegui L, Herrera H, Salces I, Rebato E. Comparison of predicted body fat percentage from anthropometric methods and from impedance in university students. Br J Nutr 2004; 92(5):827-32.

12. Goonasegaran AR, Nabila FN, Shuhada NS. Comparison of the effectiveness of body mass index and body fat percentage in defining body composition. Singapore Med 2012; 53(6):403-8.

13. Edmonds MJ, Ferreira KJ, Nikiforuk EA, Finnie
AK, Leavey SH, Duncan AM, et al. Body weight and percent body fat increase during the transition from high school to university in females. J Am Diet Assoc 2008; 108(6):1033-7.

14. Farajian P, Renti E, Manios Y. Obesity indices in relation to cardiovascular disease risk factors among young adult female students. Br J Nutr 2008; 99(4):918-24.

15. Mohammadi M, Mahmoodi Darvishani S, Mirzaei M. Bahrololoomi Z. Sheikhi A, Bidbozorg $\mathrm{H}$, et al. The Prevalence of Overweight and Obesity among Dental Students Yazd University of Medical Sciences of Yazd in 2014. Journal of Rafsanjan University of Medical Sciences 2015; 14(3):189-98.

16. Anderson DA, Shapiro JR, Lundgren JD. The freshman year of college as a critical period for weight gain: an initial evaluation. Eat Behav 2003; 4(4):363-7.

17. Salem Z, Sheikh Fathollahi M, Khatami F, Iranmanesh F, Rezaeian M. Survey of anthropometric indices and body composition changes at the End of the Second Semester, among Medical Students Entranced at Rafsanjan University of Medical Sciences in 2012. Journal of Rafsanjan University of Medical Sciences. 2014; 13(5):407-18.

18. Ross AC, Caballero B, Cousins RJ, Tuker Kl. Zegler TR. Modern nutrition in health and disease. $13^{\text {th }}$ ed. Philadelphia: Williams \&Wilkins; 2014. P: 643-5.

19. Ford ES. Prevalence of the metabolic syndrome defined by the International Diabetes Federation among adults in the U.S. Diabetes Care 2005; 28(11):2745-9.

20. Shimbo S, Zhang ZW, Matsuda-Inoguchi N, Higashikawa K, Nakatsuka H, Watanabe T, et al. Effects of life away from home and physical exercise on nutrient intake and blood/serum parameters among girl students in Japan. Tohoku J Exp Med 2004; 203(4):275-86.

21. Newton AL. Freshman versus Sophomore Year Changes in Body Weight and Composition. [MSc thesis]. Auburn University: Alabama; 2010.

22. Papadaki A, Hondros G, A Scott J, Kapsokefalou M. Eating habits of university students living at, or away from home in Greece. Appetite 2007; 49(1):169-76.

23. Dissing AS1, Bak NH, Pedersen LE, Petersson BH. Female medical students are estimated to have a higher risk for developing eating disorders than male medical students. Dan Med Bull 2011; 58(1): A4207.

24. Levitsky DA, Halbmaier CA, Mrdjenovi G. The freshman weight gain: a model for the study of the epidemic of obesity. Int J Obes Relat Metab Disord 2004; 28(11):1435-42. 